\title{
Multiplex End-Point PCR for the Detection of Three Species of Ophiosphaerella Causing Spring Dead Spot of Bermudagrass
}

\author{
J. Francisco Iturralde Martinez, ${ }^{1}$ Francisco J. Flores, ${ }^{1,2, \dagger}$ Alma R. Koch, ${ }^{1}$ Carla D. Garzón, ${ }^{3}$ and Nathan R. Walker ${ }^{3}$ \\ ${ }^{1}$ Departamento de Ciencias de la Vida y la Agricultura, Universidad de las Fuerzas Armadas ESPE, Sangolquí, 170501, Ecuador \\ ${ }^{2}$ Centro de Investigación de Alimentos, CIAL, Facultad de Ciencias de la Ingeniería e Industrias, Universidad Tecnológica \\ Equinoccial, Quito, 170147, Ecuador \\ ${ }^{3}$ Department of Entomology and Plant Pathology, Oklahoma State University, Stillwater, OK 74078, U.S.A.
}

\begin{abstract}
A multiplex end-point polymerase chain reaction (PCR) assay was developed for identifying the three-fungal species in the genus Ophiosphaerella that cause spring dead spot (SDS), a devastating disease of bermudagrass. These fungi are difficult to identify by morphology because they seldom produce pseudothecia. To achieve species-specific diagnosis, three pairs of primers were designed to identify fungal isolates and detect the pathogen in infected roots. The internal transcribed spacer region, the translation elongation factor 1- $\alpha$, and the RNA polymerase II second-largest subunit were selected as targets and served as templates for the design of each primer pair. To achieve uniform melting temperatures, three to five random nucleotide extensions (flaps)

to optimize specificity and sensitivity of the multiplex reaction. Primers were tested in multiplex on DNA extracted from axenic fungal cultures and from field-collected infected and uninfected roots. A distinct amplicon was produced for each Ophiosphaerella sp. tested. The DNA from Ophiosphaerella close relatives and other common bermudagrass pathogens did not amplify during the multiplex assay. Metagenomic DNA from infected bermudagrass produced species-specific amplicons while DNA extracted from noninfected roots did not. This multiplex end-point PCR approach is a sensitive and specific molecular technique that allows for correct identification of SDS-associated Ophiosphaerella spp. from field-collected roots.
\end{abstract} were added to the $5^{\prime}$ terminus of some of the designed specific primers. Temperature cycling conditions and PCR components were standardized
Keywords: fungi, pathogen detection, turf
Bermudagrasses are widely used as turf in warm regions throughout the world. The two most common types are Cynodon dactylon (L.,) Pers. and interspecific hybrids of C. dactylon $\times$ C. transvaalensis (Burtt-Davy). The fine-textured, dark-green interspecific hybrids are widely used on golf courses, lawns, and sport fields due to their high shoot density, aggressive growth, and pest and disease tolerance (Tredway et al. 2009).

Spring dead spot (SDS) is one of the most damaging diseases of bermudagrass where cold temperatures induce plant dormancy. The disease is caused by three fungal species in the ascomycete genus Ophiosphaerella: Ophiosphaerella herpotricha (Fr.) J. Walker; $O$. korrae (J. Walker \& A. M. Sm. bis) Shoemaker and C. E. Babc., and $O$. narmari (J. Walker \& A. M. Sm. bis) H. C. Wetzel, Hubert, and Tisserat (Endo et al. 1985; Smiley et al. 2005; Smith 1965; Tisserat et al. 1989; Wetzel et al. 1999). Genus Ophiosphaerella is a member of the Pleosporales family, which includes a wide variety of plant pathogens and facultative saprophytes. During periods of cool temperatures, the fungi colonize the roots, stolons, and rhizomes of the grass, which can lead to necrosis and lesions prior to cold temperature-induced dormancy. In the spring, once temperatures increase, plant regrowth originates from stolons and rhizomes; however, stolons and rhizomes that were colonized by the pathogenic fungi do not survive winter dormancy. As healthy grass resumes growth in the spring, SDS symptoms appear as dead plants in circular or semicircular patches, extending from a few centimeters to more than a meter in diameter (Wadsworth and Young 1960). Field evaluations have shown that $O$. herpotricha is the most aggressive of the three species, followed by $O$. korrae, and

${ }^{\dagger}$ Corresponding author: F. J. Flores; fjflores2@espe.edu.ec

The author(s) declare no conflict of interest.

Accepted for publication 14 March 2019.

() 2019 The American Phytopathological Society
O. narmari (Iriarte et al. 2005). For smaller dead patches, reestablishment of turf may be achieved in a few months; however, for larger patches, this may take the entire growing season. In addition to the dead grass, weed establishment in the dead areas is common, requires additional herbicide applications, and can compete with the regrowth of bermudagrass.

Researchers, diagnosticians, and turfgrass managers may need to know the species of Ophiosphaerella present at a given location because differences in virulence among species have been reported (Iriarte et al. 2005; Tisserat et al. 1989; Tredway et al. 2008). Traditional identification requires the fungi to be directly isolated from colonized living plant tissue. Ophiosphaerella spp. are slow-growing fungi (Iriarte et al. 2004) and other common, faster-growing fungi associated with bermudagrass make recovery of pure cultures difficult. When isolates of Ophiosphaerella are recovered, traditional morphological-based identification and discrimination among species is not possible, given that the fungi rarely produce ascospores or other diagnostic structures. Therefore, DNA sequence analysis of ribosomal DNA (rDNA) genes is routinely used for species identification.

Development of polymerase chain reaction (PCR)-based methods to quickly identify species of Ophiosphaerella have been previously conducted (O'Gorman et al. 1994; Tisserat et al. 1994; Wetzel et al. 1999) and targeted conserved rDNA regions. Primers LK17S and 5.8SC developed by O'Gorman et al. (1994), targeted conserved regions of the $18 \mathrm{~S}$ and 5.8S rDNA of $O$. korrae. Primers OHITS1 and OHITS2 for $O$. herpotricha and OKITS1 and OKITS2 for $O$. korrae were based on the internal transcribed spacer (ITS) region and can discriminate these two species (Tisserat et al. 1994). Wetzel et al. (1999) developed the primers OnITS1 and OnITS2 from the ITS1 and ITS2 regions to distinguish $O$. narmari from $O$. herpotricha and $O$. korrae.

Although the primers developed by O'Gorman et al. (1994) and Tisserat et al. (1994) were able to amplify the respective fungal DNA from naturally infected and inoculated plants, they require separate reactions for each primer pair, making screening of large numbers of plant samples costly. One methodological alternative to 
reduce diagnostic costs and effort is multiplex end-point PCR. This PCR variant includes two or more primer pairs per reaction, allowing detection and discrimination of multiple target organisms in a single reaction (Henegariu et al. 1997).

Multiplex end-point PCR primers are designed with similar or very close melting temperatures and PCR conditions are optimized in order to obtain specific target amplification using the same annealing temperature for all the primer sets included in the reaction (AbdElmagid et al. 2013; Elnifro et al. 2000; Henegariu et al. 1997). PCR targets are usually resolved in agarose or polyacrylamide gels and visualized using either UV-light or visible-light photography. By reducing sample processing time and effort, this practical approach can also reduce overall diagnostic costs. Multiplex end-point PCR has been successfully used for identification of diverse plant pathogens, including fungi (Abd-Elmagid et al. 2013; Côté et al. 2004; Elnifro et al. 2000; Schaad et al. 2003). The objective of this study was to develop primers that could discriminate the three species of Ophiosphaerella in plants using multiplex end-point PCR.

\section{Materials and Methods}

Primer design. Different loci were targeted for the design of each primer pair: the ITS region for $O$. korrae, the translation elongation factor $1-\alpha(E F 1 \alpha)$ for $O$. herpotricha, and the RNA polymerase II second-largest subunit (RPB2) for O. narmari. Geneious V. 6.0.6 (Kearse et al. 2012) was used for DNA sequence alignments. Sequences from SDS-causing species and closely related fungi were obtained from the National Center for Biotechnology Information's GenBank. For each individual locus, a minimum of 80 sequences from diverse sources was aligned to identify conserved motifs that were exclusive for each species. Primers that included such motifs at the $3^{\prime}$ end were designed. The online bioinformatics tools Multiple Primer Analyzer (https://www.thermofisher.com/us/en/home/brands/ thermo-scientific/molecular-biology/molecular-biology-learning-center/ molecular-biology-resource-library/thermo-scientific-web-tools/multipleprimer-analyzer.html) and Oligoanalyzer (https://www.idtdna.com/ site/account/login?returnurl=\%2Fcalc\%2Fanalyzer) were used for examining the potential formation of secondary structures and determining the optimal annealing temperature of specific primers in silico. To achieve uniform melting temperatures, three to five random nucleotide extensions (flaps) were added in the $5^{\prime}$ end of some of the designed specific primers. Specificity of the primers was initially assessed by blasting them against the GenBank database using Primer-BLAST (Ye et al. 2012).

In vitro testing. Sensitivity and specificity of the primers were assayed in vitro. Specificity was tested using isolates of each SDScausing species of Ophiosphaerella, as well as closely related fungal species and common fungal pathogens of bermudagrass. Pure cultures of each species that were previously identified using PCR were obtained from the culture collection of the turfgrass pathology laboratory at Oklahoma State University. Fungi were grown on semiselective medium containing potato dextrose agar amended with rifampicin at $10 \mathrm{mg} / \mathrm{liter}$, ampicillin at $250 \mathrm{mg} / \mathrm{liter}$, and fenpropatrin at $5 \mathrm{mg} / \mathrm{liter}$ (Walker et al. 2006). Hyphal tips of fungal colonies were transferred to potato dextrose broth and incubated at room temperature for 2 weeks. Mycelia were washed by filtration on Whatman 40 filter paper and lyophilized. Fungal DNA was extracted using a cetyltrimethylammonium bromide method (Weising et al. 1994), with some modifications. Extraction buffer $(1 \mathrm{ml})$, heated in a microwave for $10 \mathrm{~s}$, was added to 30 to $50 \mathrm{mg}$ of lyophilized mycelium in a 2-ml plastic tube containing one 5-mm and three 3-mm zirconia beads. Samples were bead-beaten four times for $20 \mathrm{~s}$ to disrupt cells and incubated at $58^{\circ} \mathrm{C}$ and $600 \mathrm{rpm}$ for $30 \mathrm{~min}$. Samples were centrifuged at $14,000 \times g$ for $20 \mathrm{~min}$ at $4{ }^{\circ} \mathrm{C} ; 1.5$ volumes of cold isopropanol were added to the supernatant and the samples were incubated at $4^{\circ} \mathrm{C}$ for $2 \mathrm{~h}$. The precipitated DNA was pelleted by centrifugation at $14,000 \times g$ for $20 \mathrm{~min}$ at room temperature, the supernatant was discarded, and the pellet was washed twice with $70 \%$ ethanol and resuspended with Tris-acetate-EDTA buffer.

Multiplex PCR final volumes of 25,50 , or $60 \mu$ l were assayed, each reaction contained final concentrations of 5 to $10 \mu \mathrm{M}$ each for one of six primers, $1 \times$ GoTaq Green Master Mix (Promega Corp., Madison, WI, U.S.A.), and up to $35 \mathrm{ng}$ of template DNA. The optimal final volume and concentrations were established in $60 \mu \mathrm{l}$ of $10 \mu \mathrm{M}$ primers because this combination had the brightest bands with the least amount of primer-dimers in the electrophoresis gel. A gradient of annealing temperatures was tested under the following cycling conditions: $97^{\circ} \mathrm{C}$ for $5 \mathrm{~min} ; 30$ cycles of $95^{\circ} \mathrm{C}$ for $45 \mathrm{~s}, 52$, $54.3,56,57.3$, or $58^{\circ} \mathrm{C}$ for $45 \mathrm{~s}$, and $72^{\circ} \mathrm{C}$ for $45 \mathrm{~s}$; followed by a final extension at $72^{\circ} \mathrm{C}$ for $5 \mathrm{~min}$. Therefore, the sensitivity was defined as the lowest amount of detectable DNA. In order to determine whether the assay can detect more than one Ophiosphaerella sp. in a single sample, an equimolar mixture of DNA from the three species that cause SDS was also tested.

The specificity of the multiplex was tested using DNA from fungi that are closely related to genus Ophiosphaerella or may live in the rhizosphere of bermudagrass, including Phaeosphaeria nodorum, Clarireedia jacksonii (syn. Sclerotinia homoeocarpa), Bipolaris cynodontis, B. sorokiniana, and Gaeumannomyces graminis. Serial dilutions of DNA, decreasing by one order of magnitude from 10 to $10^{-6} \mathrm{ng} / \mu \mathrm{l}$, were prepared, and served as templates for testing the sensitivity of the reaction on each species. For all cases, amplicons were resolved in $2 \%$ agarose gels using sodium borate (SB) electrophoresis buffer at $200 \mathrm{~V}$ for $30 \mathrm{~min}$. Cycling conditions and PCR components were standardized to optimize the concentration and quality of the amplicons.

Validation. The standardized multiplex PCR was validated on field-collected plant samples. Since samples were obtained in autumn, plants were asymptomatic (SDS manifests itself exclusively in spring). Plants were obtained in Stillwater and Broken Bow, OK in October 2015 using a 5-cm-diameter soil core. In Stillwater, samples were collected from a stand of bermudagrass at three locations where $O$. herpotricha was previously inoculated and at three locations in the same stand where disease was not present previously. Additional samples were collected in Broken Bow from a golf fairway with a history of severe SDS caused by both $O$. korrae and $O$. herpotricha. Roots were surface sterilized; the DNA was obtained as described above and used as template for the multiplex PCR assay.

\section{Results}

Primer design. In total, 45 primers with species-specific polymorphisms were designed and tested with DNA of Ophiosphaerella. Three species-specific primer pairs that did not show cross-reactivity

Table 1. Primers designed for the identification of Ophiosphaerella spp. that cause spring dead spot of bermudagrass ${ }^{\mathrm{a}}$

\begin{tabular}{|c|c|c|c|c|c|c|}
\hline Ophiosphaerella spp. & Primer & $5^{\prime}-3^{\prime}$ Sequence & $\operatorname{Tm}\left({ }^{\circ} \mathbf{C}\right)^{\mathbf{b}}$ & GC $(\%)$ & Product size (bp) & Target region \\
\hline \multirow[t]{2}{*}{ O. herpotricha } & OHERFW & CGTAATCTCCAAAGATGGCCAA & 55.2 & 45.5 & 247 & $\mathrm{EF} 1 \alpha$ \\
\hline & OHERRV & CACGCAGTTGGTAGAAACGT & 55.5 & 50 & & \\
\hline \multirow[t]{2}{*}{ O. korrae } & OKORFW & GGACACCCCATTGAACCTWTTT & 55.1 & 45.5 & 272 & ITS \\
\hline & OKORRV & GTTATCWGACGCAGTGGAGTG & 55.4 & 52.4 & & \\
\hline \multirow[t]{2}{*}{ O. narmari } & ONARFW & GGACTCTTCGATAGGGATATCAG & 53.7 & 47.8 & 205 & RPB2 \\
\hline & ONARRV & GCCACTCATCAAGATCTTCCG & 55.6 & 52.4 & $\ldots$ & $\ldots$ \\
\hline
\end{tabular}

\footnotetext{
a Nucleotides shown in bold are not complementary to target sequences and were added to achieve uniform melting temperatures among primers.

${ }^{\mathrm{b}}$ Melting temperature.

${ }^{c}$ Translation elongation factor 1- $\alpha$ (EF1 $\left.\alpha\right)$, internal transcribed spacer (ITS) region, and RNA polymerase II second-largest subunit (RPB2).
} 
were chosen for further experimentation (Table 1). Guanine-cytosinerich flaps, of 3 to 5 bases, were added to primers OHERFW, OHERRV, OKORRV, and ONRFW to achieve a uniform melting temperature for all the primers, which was close to $55^{\circ} \mathrm{C}$.

Secondary structure analysis showed that primers were not likely to form hairpins at temperatures above $46.6^{\circ} \mathrm{C}$. Only OHERFW and ONARFW showed a strong potential for homodimer formation with changes of Gibbs free energy of bonding $(\Delta \mathrm{Gs})$ of -13.19

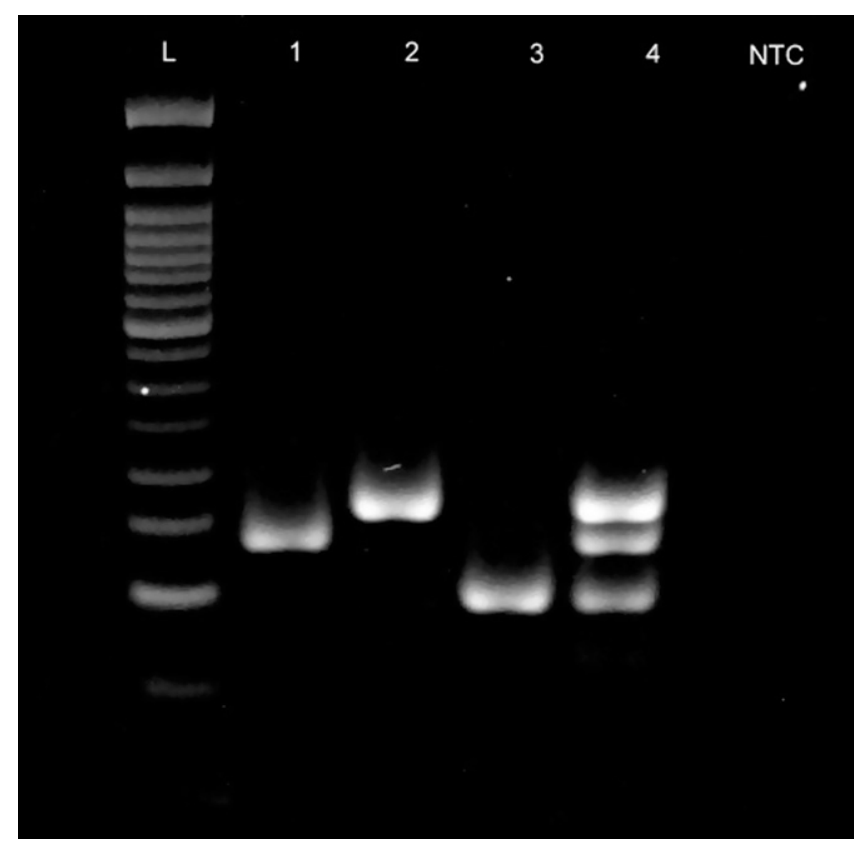

Fig. 1. Polymerase chain reaction products of the multiplex reaction for the identification of Ophiosphaerella spp. that cause spring dead spot of bermudagrass. DNA used as template from lane 1, Ophiosphaerella herpotricha; lane 2, O. korrae; lane 3, O. narmari; and lane 4, O. herpotricha +0 . korrae +0 . narmari. Lane $\mathrm{L}=$ 50-bp ladder and NTC $=$ no-template control. and $-11.71 \mathrm{kcal} / \mathrm{mol}$, respectively. Potential heterodimers with $\Delta \mathrm{G}$ below $-9 \mathrm{kcal} / \mathrm{mol}$ were not found among the six primers. In silico, all primers hybridized only with sequences corresponding to the target species. Primers for $O$. herpotricha, $O$. narmari, and $O$. korrae matched specifically with 43,8 , and 25 sequences, respectively, in GenBank.

In vitro testing. The reaction resulted in specific amplicons for each species. Products were 272, 247, and $205 \mathrm{bp}$ in size for $O$. korrae, $O$. herpotricha, and $O$. narmari, respectively, and the three bands could be resolved simultaneously in an agarose gel when a DNA mixture from all three species was used as template (Fig. 1). The highest annealing temperature at which clear bands were observed was $56^{\circ} \mathrm{C}$; at higher temperatures, the band corresponding to $O$. narmari started to fade (Fig. 2). The multiplex PCR was tested with DNA from several Ophiosphaerella isolates previously identified to the species level and it amplified products of the expected size in all cases (Fig. 3). Reactions using DNA from closely related fungi as template resulted in no amplification (Fig. 4). The highest sensitivity was attained with a reaction volume of $60 \mu \mathrm{l}$ and a final concentration of $5 \mu \mathrm{M}$ for each of the six primers used in multiplex, detecting the presence of $O$. korrae DNA down to a concentration of $1 \mathrm{pg} / \mu \mathrm{l}$ while the detection limit for $O$. herpotricha and $O$. narmari was 10 $\mathrm{pg} / \mu \mathrm{l}$. The simultaneous detection of the three species using DNA mixtures was not possible at concentrations below $10 \mathrm{ng} / \mu \mathrm{l}$.

Validation. The DNA extracted from plants at concentrations between 25 and $35 \mathrm{ng} / \mu \mathrm{l}$ was obtained from partially homogenized root tissues. The multiplex assay produced the expected 247-bp amplicons for the six samples taken from locations that were previously inoculated with $O$. herpotricha (Fig. 3). Ophiosphaerella spp. were detected in three of the seven samples from a fairway with history of SDS; two of these samples contained $O$. herpotricha and one O. korrae. There was no amplification for samples collected from locations with no history of SDS.

\section{Discussion}

From 43 primers designed that were specific for either one of the three Ophiosphaerella spp. under study, only three pairs showed no cross-reaction in vitro. Cross-reaction was significantly reduced when each pair of specific primers targeted different loci (results

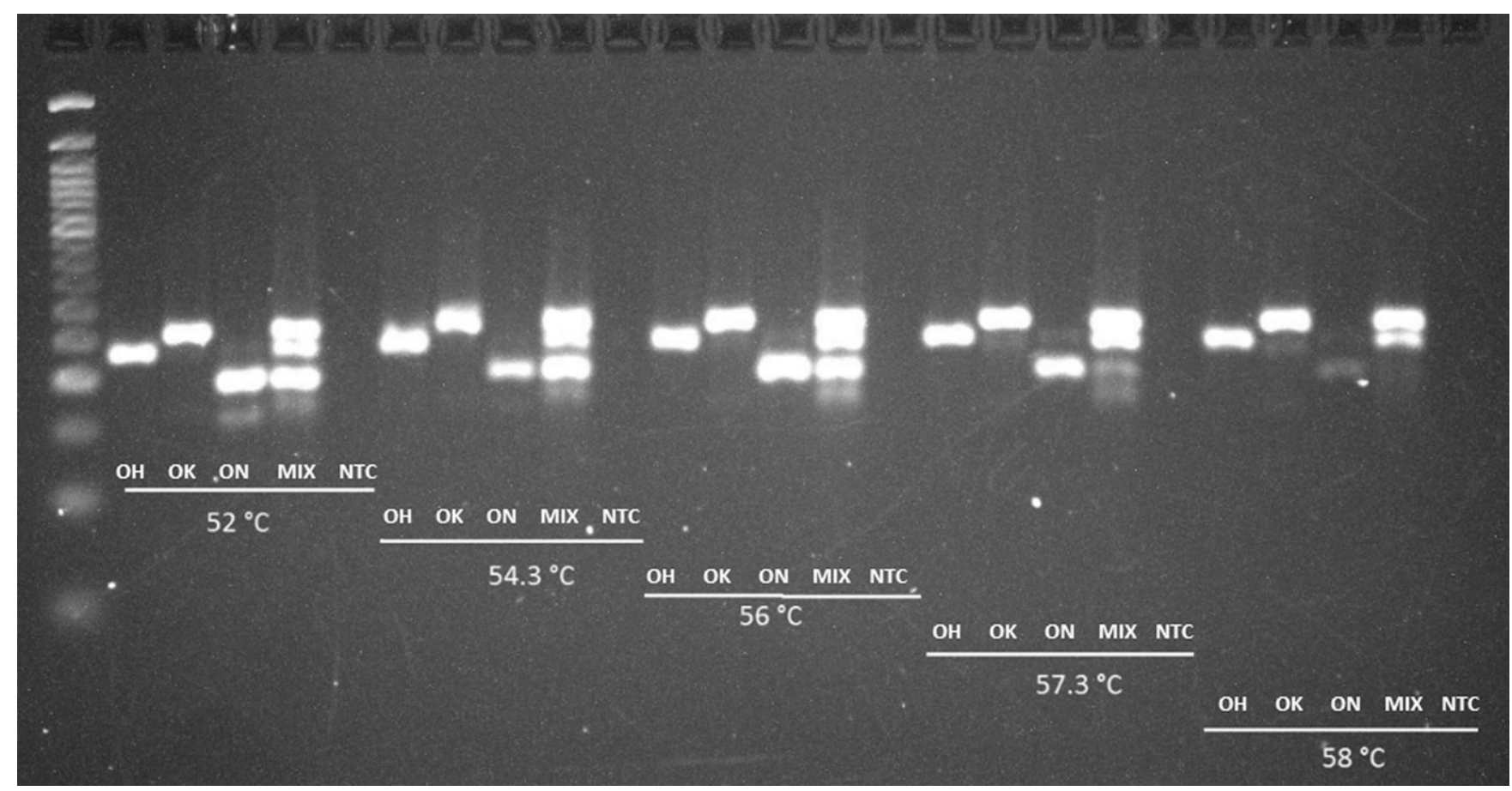

Fig. 2. Annealing temperature gradient for the multiplex reaction for the identification of Ophiosphaerella spp. that cause spring dead spot of bermudagrass (50-bp ladder). For each temperature, left to right, DNA template from Ophiosphaerella herpotricha $(\mathrm{OH}), 0$. korrae (OK), O. narmari (ON), O. herpotricha + O. korrae + O. narmari (MIX), and no-template control (NTC). 
not shown). Single mismatches around or near to $3^{\prime}$ end prevent primer annealing and affected the efficiency of the reaction (Kwok et al. 1990). A minimum of three complementary nucleotides at the $3^{\prime}$ end of the primer are required for successful amplification of a target sequence (Sommer and Tautz 1989). Even though SDScausing Ophiosphaerella spp. are closely related, and there are few species-specific polymorphisms that can be exploited for primer design, the three primer pairs selected for the multiplex PCR assay targeted sequences that included at least one polymorphic site at the $3^{\prime}$ end to avoid mispriming. Complementarity at the primer $5^{\prime}$ end was shown to be unnecessary for specificity, and the addition of noncomplementary nucleotides at this end helped achieve uniform annealing temperatures for all primers. The addition of flaps also rendered primers within the recommended length and annealing temperature range for oligonucleotides used in a multiplex reaction (Henegariu et al. 1997).

$O$. korrae primers were 100 -fold more sensitive than $O$. herpotricha and $O$. narmari primers because the former amplify part of the rDNA, for which fungal genomes can have hundreds of copies (Black et al. 2013), while the latter target single-copy loci RPB2 and EF1 $\alpha$. The rDNA has been the sole target of previously reported species-specific primers for detection of Ophiosphaerella spp. (O’Gorman et al. 1994; Tisserat et al. 1994; Wetzel et al. 1999), which had sensitivity limits similar to the ones we report for $O$. korrae . A multiplex assay for the detection of Ophiosphaerella spp. was not available until now due to the lack of sequence data on different loci from this genus. Previously described specific primers targeted the same polymorphic sites for the different species, rendering products of the same size (Tisserat et al. 1994); hence the need for separate assays.

This multiplex assay was able to detect and discriminate all three Ophiosphaerella spp. simultaneously when the total target DNA concentration was at least $10 \mathrm{ng} / \mu \mathrm{l}$. Phylogenetic analysis of Ophiosphaerella revealed the presence of two distinct clades within O. korrae (Flores et al. 2017b). Specific primer hybridization to the ITS region of individuals from both clades was achieved by including a single degenerate nucleotide on primers OKORFW and OKORRV. In silico analysis showed that, during the annealing step at $56^{\circ} \mathrm{C}$, the oligonucleotides in the reaction mix should be linearized and would hybridize with the target DNA efficiently. Primers were designed to avoid hetero- and homodimer formation and are unlikely to form hairpins at temperatures above $50^{\circ} \mathrm{C}$.
Among the oligonucleotides used in the multiplex reaction, $O$. korrae primers showed the lowest capacity to form dimers, which can also explain their enhanced sensitivity. Although primers OHERFW and ONARFW showed strong potential for homodimer formation, none were observed at the optimized PCR assay conditions with one target DNA. Faint unspecific fragments were visible in some reactions that included DNA mixtures of the three Ophiosphaerella spp. when highly concentrated products were loaded to agarose gels (not shown). Unspecific fragments were not observed during assay validation.

SDS symptoms appear when bermudagrass comes back from dormancy but the causal agent persists in the root system all year long (Perry et al. 2010; Walker 2006). Using multiplex PCR in a diagnostic test may detect different species of Ophiosphaerella in a single reaction from whole DNA extracted from field samples even if they are asymptomatic. In addition, the actual host-fungus association host range for Ophiosphaerella spp. is cryptic and not fully characterized (Flores et al. 2017a). This diagnostic test could be used on other grass species to further define the range of plants Ophiosphaerella colonizes.

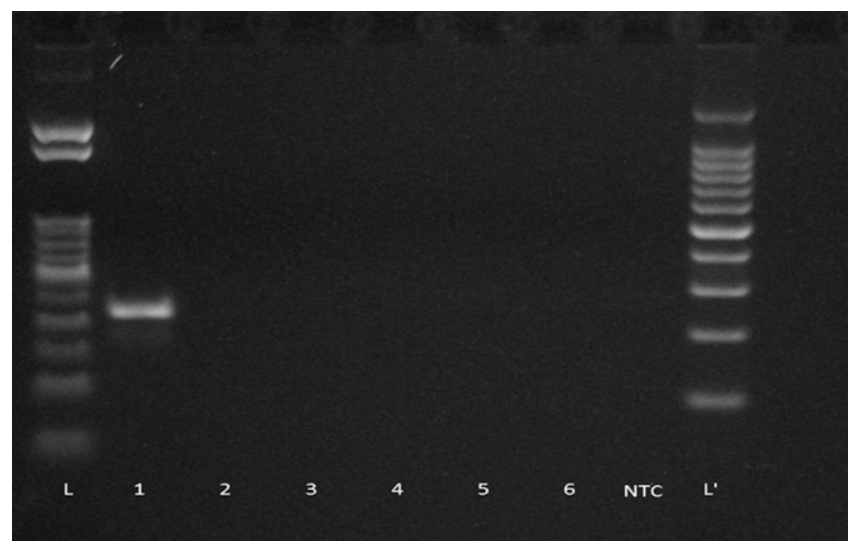

Fig. 4. Cross reactivity of the primers tested with closely related fungi. Lane L, 100-bp ladder; lane 1, Ophiosphaerella narmari isolate AUS58; lane 2, Gaeumannomyces graminis; lane 3, Phaeosphaeria nodorum; lane 4, Bipolaris sorokiniana; lane 5, Bipolaris cynodontis; lane 6, Clarireedia jacksonii; and lane NTC, no-template control; L, 50-bp ladder; L', 100-bp ladder.

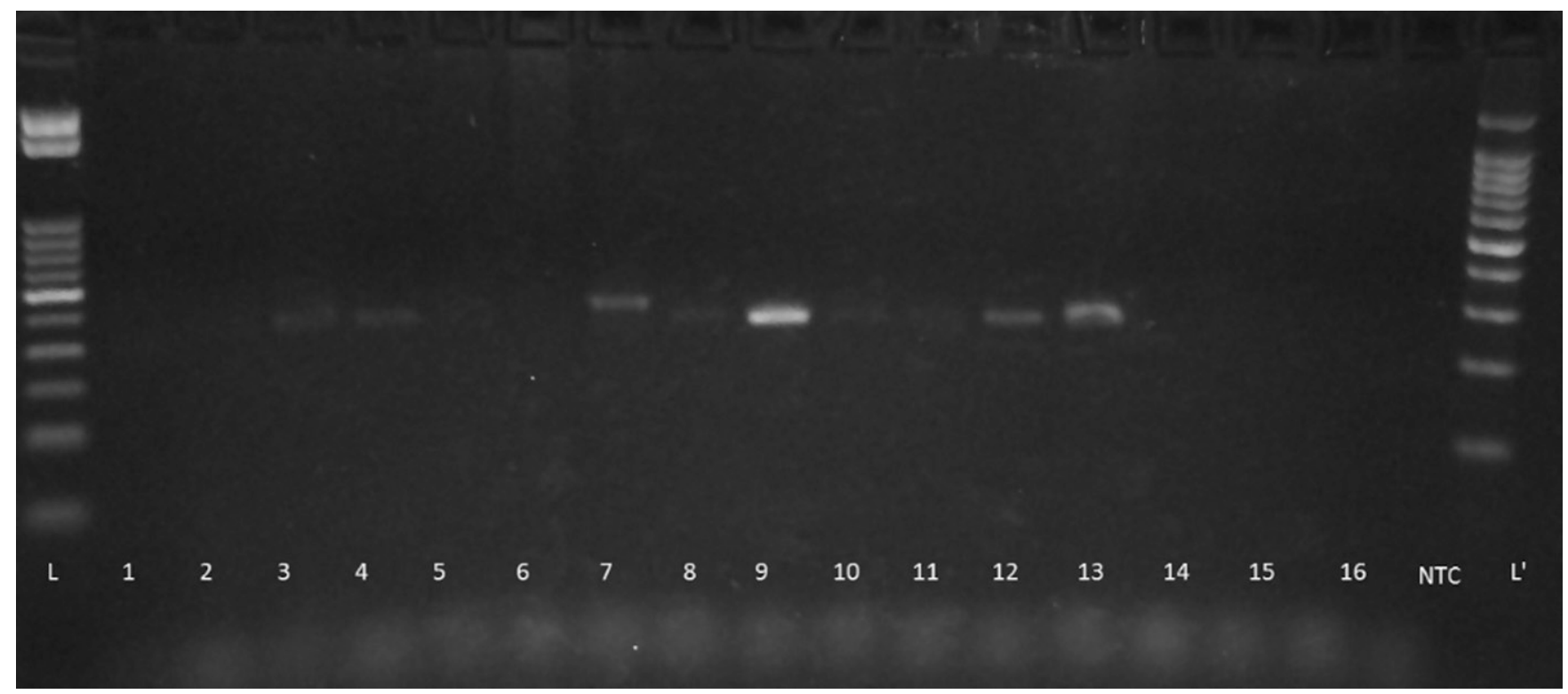

Fig. 3. Validation of the multiplex polymerase chain reaction designed to detect Ophiosphaerella spp. that cause spring dead spot (SDS) of bermudagrass. The multiplex was tested with samples from lanes 1 to 7 , a field with history of SDS; lanes 8 to 13, locations previously inoculated with Ophiosphaerella herpotricha; and lanes 14 to 16 , locations with no history of SDS. Lane $\mathrm{L}=50$-bp ladder and NTC $=$ no-template control. 
Results show the multiplex end-point PCR reported herein is capable of producing a unique amplicon for each one of the three SDSassociated Ophiosphaerella spp. There is no cross-reaction with closely related fungi or fungi commonly found associated with bermudagrass and the test is sensitive enough to detect the pathogens directly from field samples, making this method a very useful tool for timely diagnosis.

\section{Literature Cited}

Abd-Elmagid, A., Garrido, P. A., Hunger, R., Lyles, J. L., Mansfield, M. A., Gugino, B. K., Smith, D. L., Melouk, H. A., and Garzon, C. D. 2013. Discriminatory simplex and multiplex PCR for four species of the genus Sclerotinia. J. Microbiol. Methods 92:293-300.

Black, J., Dean, T., Byfield, G., Foarde, K., and Menetrez, M. 2013. Determining fungi rRNA copy number by PCR. J. Biomol. Tech. 24:32-38.

Côté, M.J., Tardif, M.C., and Meldrum, A. J. 2004. Identification of Monilinia fructigena, M. fructicola, M. laxa, and Monilia polystroma on inoculated and naturally infected fruit using multiplex PCR. Plant Dis. 88:1219-1225.

Elnifro, E. M., Ashshi, A. M., Cooper, R. J., and Klapper, P. E. 2000. Multiplex PCR: Optimization and application in diagnostic virology. Clin. Microbiol. Rev. 13:559-570.

Endo, R. M., Ohr, H. D., and Krausman, E. M. 1985. Leptosphaeria korrae, a cause of the spring dead spot disease of bermudagrass in California. Plant Dis. 69:235-237.

Flores, F. J., Marek, S. M., Anderson, J. A., Mitchell, T. K., Moreno-Zambrano, M., and Walker, N. R. 2017a. Reactive oxygen species production and alternative hosts of spring dead spot-causing fungi. Int. Turfgrass Soc. Res. J. 13:213-224.

Flores, F. J., Marek, S. M., Orquera, G., and Walker, N. R. 2017b. Molecular identification and multilocus phylogeny of Ophiosphaerella species associated with spring dead spot of Bermudagrass. Crop Sci. 57(S):249-261.

Henegariu, O., Heerema, N., Dlouhy, S., Vance, G., and Vogt, P. 1997. Multiplex PCR: Critical parameters and step-by-step protocol. Biotechniques 23:504-511.

Iriarte, F. B., Wetzel, H. C., Fry, J. D., Martin, D. L., and Tisserat, N. A. 2004. Genetic diversity and aggressiveness of Ophiosphaerella korrae, a cause of spring dead spot of bermudagrass. Plant Dis. 88:1341-1346.

Iriarte, F. B., Wetzel, H. C., Fry, J. D., Martin, D. L., Vincelli, P., Dixon, E. W., and Tisserat, N. A. 2005. Aggressiveness of spring dead spot pathogens to bermudagrass. Int. Turfgrass Soc. Res. J. 10:258-264.

Kearse, M., Moir, R., Wilson, A., Stones-Havas, S., Cheung, M., Sturrock, S., Buxton, S., Cooper, A., Markowitz, S., Duran, C., Thierer, T., Ashton, B., Meintjes, P., and Drummond, A. 2012. Geneious Basic: An integrated and extendable desktop software platform for the organization and analysis of sequence data. Bioinformatics 28:1647-1649.

Kwok, S., Kellogg, D. E., McKinney, N., Spasic, D., Goda, L., Levenson, C., and Sninsky, J. J. 1990. Effects of primer-template mismatches on the polymerase chain reaction: Human immunodeficiency virus type 1 model studies Nucleic Acids Res. 18:999-1005.

O'Gorman, D., Xue, B., Hsiang, T., and Goodwin, P. H. 1994. Detection of Leptosphaeria korrae with the polymerase chain reaction and primers from the ribosomal internal transcribed spacers. Can. J. Bot. 72:342-346.

Perry, D., Tomaso-Peterson, M., and Baird, R. 2010. Seasonal variation in frequency of isolation of Ophiosphaerella korrae from bermudagrass roots in Mississippi and pathogenicity and optimal growth of selected isolates. Mycopathologia 169:395-402.

Schaad, N. W., Frederick, R. D., Shaw, J., Schneider, W. L., Hickson, R., Petrillo, M. D., and Luster, D. G. 2003. Advances in molecular-based diagnostics in meeting crop biosecurity and phytosanitary issues. Annu. Rev. Phytopathol. 41:305-324.

Smiley, R. W., Dernoeden, P. H., and Clarke, B. B. 2005. Compendium of Turfgrass Diseases, 3ed ed. American Phytopathological Society, St. Paul, MN, U.S.A.

Smith, A. M. 1965. Ophiobolus herpotrichus a cause of spring dead spot in couch turf. Agric. Gaz. N. S. W. 76:753-758.

Sommer, R., and Tautz, D. 1989. Minimal homology requirements for PCR primers. Nucleic Acids Res. 17:6749.

Tisserat, N. A., Hulbert, S. H., and Sauer, K. M. 1994. Selective amplification of rDNA internal transcribed spacer regions to detect Ophiosphaerella korrae and $O$. herpotricha. Phytopathology 84:478-482.

Tisserat, N. A., Pair, J. C., and Nus, A. 1989. Ophiosphaerella herpotricha, a cause of spring dead spot of bermudagrass in Kansas. Plant Dis. 73:933-937.

Tredway, L. P., Butler, E. L., Soika, M. D., and Bunting, M. L. 2008. Etiology and management of spring dead spot of hybrid bermudagrass in North Carolina, USA. Acta Hortic. 783:535-546.

Tredway, L. P., Tomaso-Peterson, M., Perry, H., and Walker, N. R. 2009. Spring dead spot of bermudagrass: A challenge for researchers and turfgrass managers. Plant Health Prog. 10. doi:10.1094/PHP-2009-0710-01-RV

Wadsworth, D. F., and Young, H. C. 1960. Spring dead spot of bermudagrass Plant Dis. Rep. 44:516-518.

Walker, N. R. 2006. Viability of dormant bermudagrass in spring dead spot patches caused by Ophiosphaerella herpotricha during winter months. (Abstr.) Phytopathology 96:S119.

Walker, N. R., Mitchell, T. K., Morton, A. N., and Marek, S. M. 2006. Influence of temperature and time of year on colonization of bermudagrass roots by Ophiosphaerella herpotricha. Plant Dis. 90:1326-1330.

Weising, K., Nybom, H., Pfenninger, M., Wolff, K., and Meyer, W. 1994. DNA Fingerprinting in Plants and Fungi. CRC Press, Boca Raton, FL, U.S.A.

Wetzel, H. C., Hulbert, S. H., and Tissert, N. A. 1999. Molecular evidence for the presence of Ophiosphaerella narmari n. comb., a cause of spring dead spot of bermuda grass, in North America. Mycol. Res. 103:981-989.

Ye, J., Coulouris, G., Zaretskaya, I., Cutcutache, I., Rozen, S., and Madden, T. L. 2012. Primer-BLAST: A tool to design target-specific primers for polymerase chain reaction. BMC Bioinf. 13:134. 